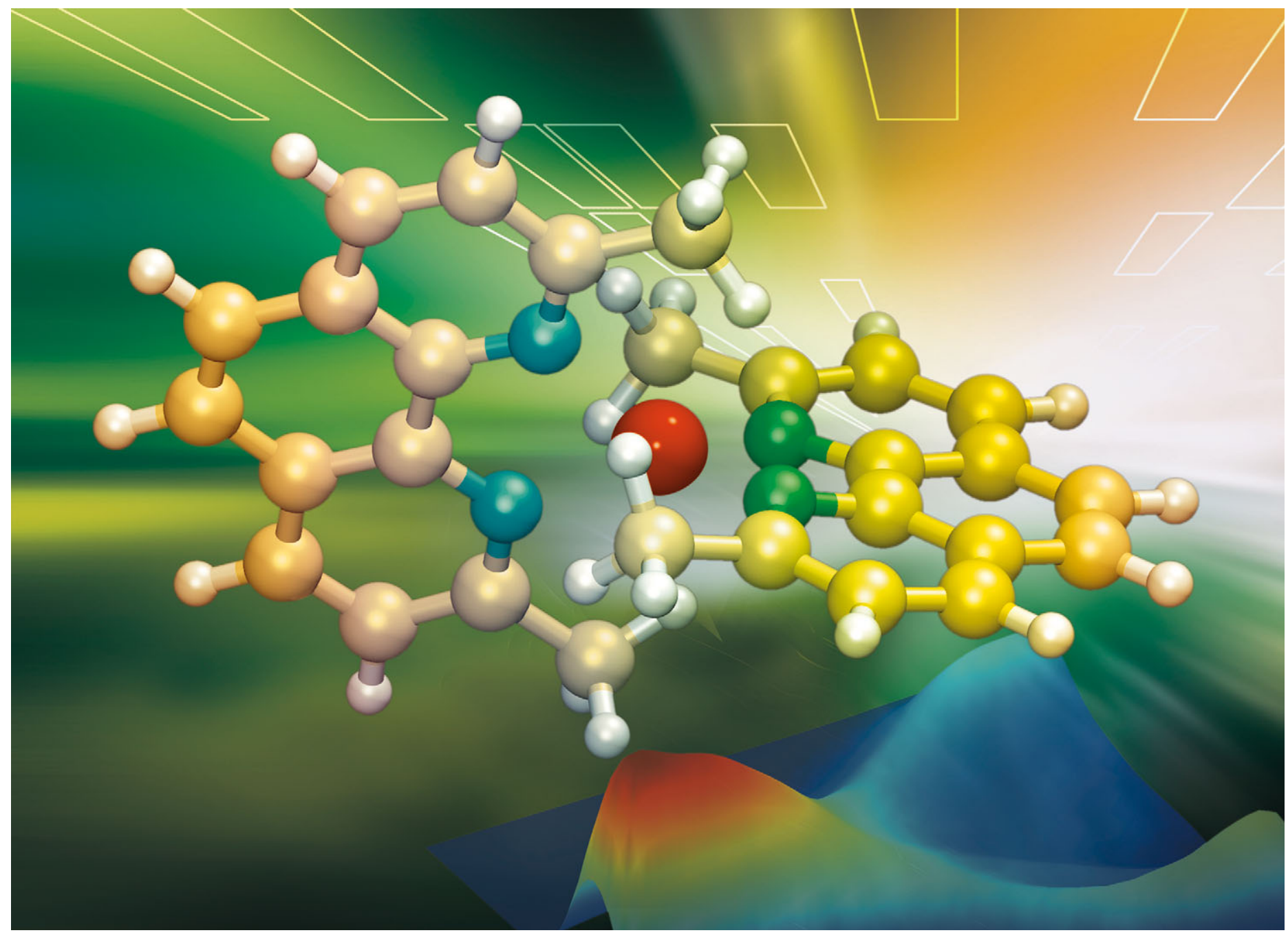

Showcasing research from the laboratory of

Prof. Dr Zhenggang Lan at Qingdao Institute of Bioenergy and Bioprocess Technology, Chinese Academy of Sciences, China.

Title: Ultrafast structural flattening motion in photoinduced excited state dynamics of a bis(diimine) copper(I) complex

The photoinduced ultrafast dynamics of a prototypical $\mathrm{Cu}(\mathrm{I})$ complex, $\left[\mathrm{Cu}(\mathrm{dmp})_{2}\right]^{+}(\mathrm{dmp}=2,9$-dimethyl-1,10-phenanthroline), is investigated by the theoretical simulation of excited-state dynamics. Our simulation clearly reveals the physical insight on photoinduced structural evolution, namely flattening process, of this $\mathrm{Cu}(\mathrm{I})$ complex on electronically excited state at all atomic levels. This theoretical work not only provides an interesting understanding of experimental works on the $\mathrm{Cu}(\mathrm{I})$ complexes, but also demonstrates the essential role of the state-of-art dynamical simulation in the exploration of the photochemistry of transition metal complexes.

\section{As featured in:}

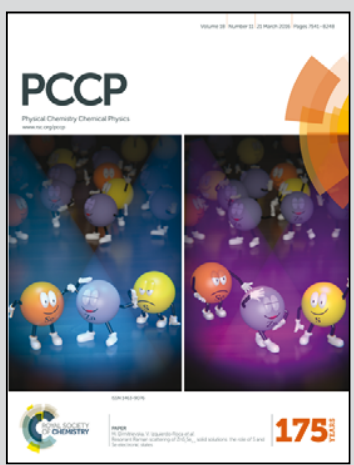

See Likai Du and Zhenggang Lan, Phys. Chem. Chem. Phys., 2016, 18, 7641.

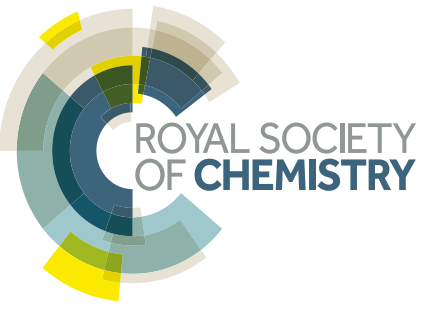


CrossMark \& click for updates

Cite this: Phys. Chem. Chem. Phys., 2016, 18, 7641

Received 10th November 2015, Accepted 15th December 2015

DOI: $10.1039 / \mathrm{c5cp06861d}$

www.rsc.org/pccp

\title{
Ultrafast structural flattening motion in photoinduced excited state dynamics of a bis(diimine) copper(।) complex $\dagger$
}

\author{
Likai $\mathrm{Du}^{\mathrm{abc}}$ and Zhenggang Lan*abc
}

\begin{abstract}
The ultrafast photoinduced structural change dynamics of a prototypical $\mathrm{Cu}(\mathrm{I})$ complex, namely, $\left[\mathrm{Cu}(\mathrm{dmp})_{2}\right]^{+}$ ( $\mathrm{dmp}=2,9$-dimethyl-1,10-phenanthroline), is investigated based on the theoretical analysis of static and dynamical calculations at the all-atomic level. This work mainly focuses on the intriguing structural flattening features of $\left[\mathrm{Cu}(\mathrm{dmp})_{2}\right]^{+}$occurring in the metal-to-ligand charge transfer singlet excited state $\left({ }^{1} \mathrm{MLCT}\right)$ on the sub-picosecond timescale. Our estimated time constant ( $675 \mathrm{fs}$ ) of this "flattening" motion is in good agreement with recent experimental values. The full-dimensional excited-state nonadiabatic dynamic simulation provides a direct view of the ultrafast photoinduced events of $\left[\mathrm{Cu}(\mathrm{dmp})_{2}\right]^{+}$, especially, the structural flattening mechanism on the $\mathrm{S}_{1}$ state. Several molecular motions (such as $\mathrm{Cu}-\mathrm{N}$ stretching, the motion of the substituted groups etc.) with distinguishable time scales are involved in the flattening dynamics. The Fourier transformation of the time-dependent oscillation of the $\mathrm{Cu}-\mathrm{N}$ bond and the $\mathrm{N}-\mathrm{Cu}-\mathrm{N}$ bond angle provides consistent conclusions with the experimental spectrum analysis. These dynamics details imply that various nuclear motions are strongly coupled in the high-dimensional excited-state potential energy surface responsible for the geometrical evolution of $\left[\mathrm{Cu}(\mathrm{dmp})_{2}\right]^{+}$. This work provides us a unique fundamental understanding of the ultrafast photoinduced excited-state nonadiabatic process of $\mathrm{Cu}(\mathrm{l})$ complexes and their derivatives, which should have potential impacts on various research fields, such as photo-catalysts, dye-sensitized solar cells (DSSCs), and organic light emitting diodes (OLEDs).
\end{abstract}

\section{Introduction}

The copper complexes, especially $\mathrm{Cu}(\mathrm{I})$, usually exhibit highly interesting and complicated excited state dynamics, such as metal-to-ligand charge transfer (MLCT) excitation in the visible range, long-lifetime triplet MLCT states, and photoinduced structural flattening. ${ }^{1-4}$ As a group of photovoltaic materials alternative to the relatively expensive ruthenium(II) and osmium(II) complexes, ${ }^{5-10}$ the complexes based on more abundant $\mathrm{Cu}(\mathrm{I})$ have attracted much attention due to their redox and luminescence properties potentially applicable for diverse applications, ${ }^{11-14}$ i.e. photocatalysts, ${ }^{15}$ dye-sensitized solar cells (DSSCs), ${ }^{16}$ and organic light emitting diode (OLED) materials. ${ }^{17}$ Their possible extensive

\footnotetext{
${ }^{a}$ Key Laboratory of Biobased Materials, Qingdao Institute of Bioenergy and Bioprocess Technology, Chinese Academy of Sciences, Qingdao, 266101, Shandong, People's Republic of China. E-mail: lanzg@qibebt.ac.cn; Fax: +86-532-80662778; Tel: $+86-532-80662630$

${ }^{b}$ The Qingdao Key Lab of Solar Energy Utilization and Energy Storage Technology, Qingdao Institute of Bioenergy and Bioprocess Technology, Chinese Academy of Sciences, Qingdao, 266101, Shandong, People's Republic of China

${ }^{c}$ University of Chinese Academy of Sciences, Beijing 100049,

People's Republic of China

$\dagger$ Electronic supplementary information (ESI) available. See DOI: 10.1039/c5cp06861d
}

applications have become the main driving force for large research efforts aiming at understanding their fundamental photophysical and photochemical properties. ${ }^{18,19}$

Among them, several bis(diimine) $\mathrm{Cu}(\mathrm{I})$ complexes have received significant attention due to their visible absorption and long-lived emission of the metal-to-ligand charge transfer (MLCT) states, ${ }^{20}$ which are highly suitable for photosensitizers and photocatalysts. By comparison with the well-known $\left[\mathrm{Ru}(\mathrm{bpy})_{3}\right]^{2+}$ system, ${ }^{9,21,22}$ an interesting feature of the $\mathrm{Cu}(\mathrm{I})$ complexes is their photoinduced structural change, namely "flattening" dynamics on the excited states. ${ }^{23-26}$ Upon excitation, a $d$ electron of the central $\mathrm{Cu}(\mathrm{I})$ is transferred to the ligands, and the central copper is formally oxidized from $\mathrm{Cu}(\mathrm{I})$ to $\mathrm{Cu}(\mathrm{II})$. Therefore, the geometrical evolution of the bis(diimine) $\mathrm{Cu}(\mathrm{I})$ complexes on the excited state is sometimes explained by the structural difference between tetrahedral $\mathrm{Cu}(\mathrm{I})$ complexes and square planar $\mathrm{Cu}$ (II) complexes. The former $\mathrm{Cu}(\mathrm{I})$ $\left(\mathrm{d}^{10}\right)$ mostly prefers the four-coordinated (tetrahedral) geometry, while the latter $\mathrm{Cu}(\mathrm{II})\left(\mathrm{d}^{9}\right)$ prefers a six-(distorted octahedral) or five-coordinated (square pyramidal or trigonal bipyramidal) geometry. ${ }^{27,28}$ For example, $\left[\mathrm{Cu}(\mathrm{dmp})_{2}\right]^{+}$(dmp = 2,9-dimethyl1,10-phenanthroline) is a well-known prototypical bis(diimine) $\mathrm{Cu}(\mathrm{I})$ complex (Fig. 1), which could undergo a large photoinduced structural flattening. ${ }^{20,29-31}$ 


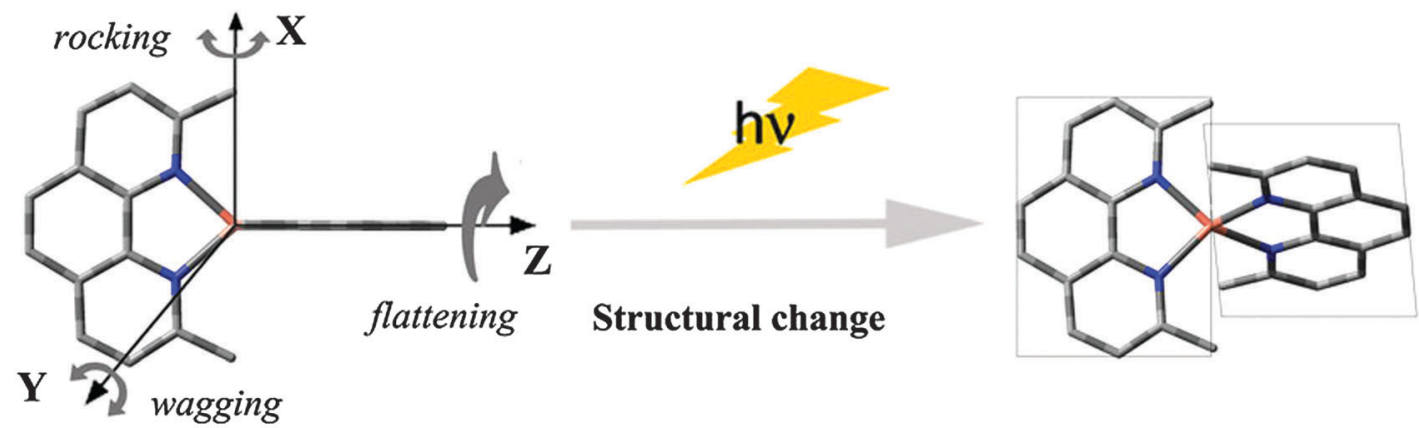

Fig. 1 Photoinduced structural flattening of $\left[\mathrm{Cu}(\mathrm{dmp})_{2}\right]^{+}$in the ${ }^{1} \mathrm{MLCT}$ excited state. The hydrogen atoms were omitted for clarify. Possible motions between $\mathrm{dmp}$ ligands, namely wagging, rocking and flattening motions, were defined.

The photochemistry and photophysics of bis(diimine) $\mathrm{Cu}(\mathrm{I})$ complexes are governed by various excited-state processes, including internal conversion (IC), structural flattening distortions, intersystem crossing (ISC), and etc. Due to their complicated ultrafast structural dynamics, a detailed understanding of these processes requires both state-of-art experimental observations and sophisticated theoretical studies. So far, the time-resolved spectroscopic investigations of $\left[\mathrm{Cu}(\mathrm{dmp})_{2}\right]^{+}$and its derivatives have been performed by a few groups. ${ }^{20,29,30,32-34,35-39}$ Typically, early ultrafast excited state dynamics of $\left[\mathrm{Cu}(\mathrm{dmp})_{2}\right]^{+}$displays two time constants, one of the order of sub-picosecond i.e. $660 \mathrm{fs,}$ $800 \mathrm{fs}$ ) and one of the order of $10-20 \mathrm{ps.}^{20,39}$ The sub-picosecond component was originally assigned to ISC in the early study of Chen et al., due to the structural similarities of $\left[\mathrm{Cu}(\mathrm{dmp})_{2}\right]^{+}$ and $\left[\mathrm{Ru}(\mathrm{bpy})_{3}\right]^{2+}$, while the longer component was assigned to structural rearrangement. ${ }^{33} \mathrm{~A}$ recent quantum wavepacket dynamics studies with a multiconfigurational time-dependent Hartree (MCTDH) approach, ${ }^{40}$ based on a reduced model Hamiltonian, also highlighted the possible role of ISC at the Franck-Condon (FC) geometry. However, the assignment of the ISC process is still an open and controversial problem. For example, Nozaki and co-workers reported different assignments, ${ }^{34}$ in which ISC was assigned to the slower time component (10-20 ps). Later, Chen and co-workers ${ }^{29}$ also reported a reversal of their previous assignments, and concluded that ISC should occur on longer time scales, much slower than the initial structural distortion. Nowadays, several groups ${ }^{20,29,31,34,38}$ usually assigned the shortest time component (a few hundred femtoseconds) to IC and structural flattening, and the longer time component (10-20 ps) to ISC. Tahara and co-workers further demonstrate that the time scales of the structural flattening and the ISC in the lowest ${ }^{1} \mathrm{MLCT}$ state are clearly well-separated, with time constants of $\sim 0.8 \mathrm{ps}$ (structural change) and $\sim 10 \mathrm{ps}$ (ISC) for a few bis(diimine) $\mathrm{Cu}(\mathrm{I})$ complexes. ${ }^{30,31}$ In theoretical aspects, despite a few uncertainties of the assignments,${ }^{40}$ it is clear that the structural flattening distortion largely weakens spin-orbital couplings, further significantly slows down the ISC process of $\left[\mathrm{Cu}(\mathrm{dmp})_{2}\right]^{+}$as the structure distorts away from the ideal tetrahedral geometry. ${ }^{29,31,34}$

Recent femtosecond time-resolved spectra demonstrated that the flattening distortion predominantly occurs in the ${ }^{1}$ MLCT state on the sub-picosecond time scale, ${ }^{30,31}$ which is a typical character in a series of $\mathrm{Cu}(\mathrm{I})$ complexes. To address this issue, we focus on the early stage of photoinduced excited-state dynamics attributable to the ultrafast IC and the structural flattening distortion. Currently, the full-dimensional excitedstate dynamics for the large transition metal complexes is still a great challenging topic. Here, the on-the-fly nonadiabatic surface hopping dynamics at the TDDFT level were performed to study the excited-state dynamics of the $\left[\mathrm{Cu}(\mathrm{dmp})_{2}\right]^{+}$complex. The on-the-fly scheme includes all nuclear degrees of freedom, which is very suitable to provide a rather illustrative picture of the large structural changes of the realistic $\left[\mathrm{Cu}(\mathrm{dmp})_{2}\right]^{+}$ complex in the ${ }^{1}$ MLCT excited state. Our calculations predicted the time constant of the "flattening" dynamics in good agreement with a series of recent experimental values..$^{20,29-31,35,38}$ Our calculations also clearly identified the role of various electronnuclei coupled motions involved in the structural flattering dynamics. This work is supposed to provide us some fundamental atomic-level insights into the excited state dynamics of the bis(diimine) $\mathrm{Cu}(\mathrm{I})$ complex in the applications of photocatalysts, dye-sensitized solar cells (DSSCs), and organic light emitting diodes (OLEDs).

\section{Methods}

The minimum-energy geometries of the $\left[\mathrm{Cu}(\mathrm{dmp})_{2}\right]^{+}$complex for the ground state $\left(\mathrm{S}_{0}\right)$ were optimized at the DFT/6-31G* level with BHandHLYP, M06-2X, and CAM-B3LYP functionals. The low-lying singlet excited state geometries and properties were computed using the TDDFT method with a few functionals (BHandHLYP, M06-2X, and CAM-B3LYP). All optimizations were performed without any symmetry constraints. The vertical excitation energies, and simulated spectra were computed at the TDDFT/6-31G* level for a few low-lying excited excited states. For validation, our results at the DFT/TDDFT level were compared with available experimental data. For the bis(diimine) $\mathrm{Cu}(\mathrm{I})$ complexes, the all electron basis sets were commonly used in recent theoretical investigations due to their good performance compared with experimental data. ${ }^{34,37}$ The similar approaches were also taken by a few of extensive benchmarking studies for the ground and excited properties of some copper complexes with various theoretical methods. ${ }^{41,42}$ Thus an all electron basis set $6-31 \mathrm{G}^{*}$ was employed here, because the computational cost 
is still acceptable in this model. Certainly, when the larger copper complexes are considered, the effective core potential of copper becomes a practical approach to speed up the electronicstructure calculations. All the above calculations were performed using the Gaussian 09 package. ${ }^{43}$

The ultrafast excited-state dynamics of the $\left[\mathrm{Cu}(\mathrm{dmp})_{2}\right]^{+}$complex was investigated using the on-the-fly surface hopping approach. Here, we give a short description of the semiclassical trajectory surface hopping procedure, ${ }^{44,45}$ especially, the on-the-fly dynamics, which have been adopted in the JADE package. ${ }^{46,47}$ In the surface hopping dynamics, the nuclear and electronic degrees of freedom are treated by classical and quantum dynamics, respectively. The motion of the nuclear degrees of freedom is represented by independent classical trajectories on the currently occupied electronic state, which is computed by the numerical integration of Newton's equations. The electronic motion is treated by the propagation of electronic wavefunction by solving the timedependent Schrödinger equation. At each time step, nonadiabatic transitions between excited states were taken into account via Tully's fewest switches approach. ${ }^{48}$ Finally a large number of trajectories were computed to achieve the final statistical meaningful results. This approach is possible to treat relatively large and realistic molecular systems with a full degree of freedom (DoF). Dynamics treatment with more accurate electronic-structure and advanced dynamical methods with full dimensionality should represent the great challenge for the future. The potential energies and nuclear gradients were computed by using TDDFT method. The numerical nonadiabatic couplings with respect to time ${ }^{45,49-51}$ were adopted in the nonadiabatic surface hopping dynamics as implemented in the JADE package, ${ }^{46}$ since the analytic nonadiabatic couplings at the TDDFT level are still not commonly available in most of the standard QC packages. The decoherence correction proposed by Granucci et $a .^{52}$ was taken and the parameter is set to $\alpha=0.1$ Hartree. The time step for the integration of classical equations was $0.5 \mathrm{fs}$ and of quantum equations, $0.005 \mathrm{fs}$. The initial geometries and velocities of the excited state dynamics simulations were generated from the Wigner distribution function ${ }^{53,54}$ of the first vibrational level of the ground electronic state. The absorption spectrum was also calculated at the TDDFT level by collecting the oscillation strength at the corresponding transition energy over a large number of sampled geometries. Starting from the initial sampling geometries of the ground state, the $\left[\mathrm{Cu}(\mathrm{dmp})_{2}\right]^{+}$complex is electronically excited to the $\mathrm{S}_{n}\left(\mathrm{~S}_{2}\right.$ or $\left.\mathrm{S}_{3}\right)$ state, as reported in the experimental studies. $^{20,29-31,33-35,38}$ And 78 trajectories starting from each state $\left(\mathrm{S}_{2} / \mathrm{S}_{3}\right)$ were calculated. The CAM-B3LYP ${ }^{55}$ and M06-2X $\mathrm{X}^{56}$ functionals were used in the TDDFT calculations. All calculations and data analysis were done within the JADE package, interfaced with the Gaussian 09 package. A few technical details in the trajectory analysis were summarized in the ESI. $\dagger$

\section{Results and discussion}

\section{The structures and properties of the $\left[\mathrm{Cu}(\mathrm{dmp})_{2}\right]^{+}$complex}

In Fig. 1, we show the optimized ground $\left(\mathrm{S}_{0}\right)$ and low-lying excited state $\left(S_{1}\right)$ geometries of $\left[\mathrm{Cu}(\mathrm{dmp})_{2}\right]^{+}$. The optimized geometry at the $\mathrm{S}_{0}$ state of $\left[\mathrm{Cu}(\mathrm{dmp})_{2}\right]^{+}$confirms the perpendicular orientation of the dmp ligands $\left(D_{2 \mathrm{~d}}\right.$ symmetry). ${ }^{3,20,34}$ The lowest singlet excited state $\left(\mathrm{S}_{1}\right)$ of the $\left[\mathrm{Cu}(\mathrm{dmp})_{2}\right]^{+}$complex was optimized without any symmetry constraints. A significant geometric distortion between the ground and the excited state was observed (Fig. 1). The interligand dihedral angle $(\varphi)$ was $70.4^{\circ}$ at the $S_{1}$ minima. The details of the calculations of the interligand dihedral angle $(\varphi)$ were given in the ESI. $\dagger$ The critical geometric parameters with CAM-B3LYP, M06-2X and BHandHLYP functionals were also collected in Table $\mathrm{S} 1$ (ESI $\dagger$ ). Interestingly, the $\mathrm{Cu}-\mathrm{N}$ bond length for each ligand is split into two groups on the excitedstate minima. Two $\mathrm{Cu}-\mathrm{N}$ bonds associated with one ligand become shorter, while the other two $\mathrm{Cu}-\mathrm{N}$ bonds become longer. This indicates that the geometries of two ligands become not fully equivalent at the $S_{1}$ minima. The geometry evolution on the excited state should be attributed to different electronic transitions at the perpendicular and flattened geometry (Fig. S1, $\mathrm{ESI}+$ ). At the perpendicular geometry, the LUMO orbital is delocalized over both dmp ligands. Meanwhile, at the flattened geometry, the LUMO orbital is localized on one dmp ligand, and the excitation was from the copper ion (HOMO) to one of the dmp ligands (LUMO). This asymmetrical excitation also explains the slight geometrical difference of two ligands at the $S_{1}$ minima.

We then analyzed the nature of low-lying singlet excited states with the transition density analysis approach. ${ }^{57-60}$ Two blocks (the copper ion and dmp ligands) were used to build intra-unit and inter-unit transition probabilities. It is clear that the low-lying excited states $\left(\mathrm{S}_{1}, \mathrm{~S}_{2}\right.$, and $\left.\mathrm{S}_{3}\right)$ are typically MLCT states (Fig. S2, ESI $\dagger$ ). Table 1 lists the calculated and experimental excitation energies. For $\left[\mathrm{Cu}(\mathrm{dmp})_{2}\right]^{+}$, the experimental assignment of the ${ }^{1}$ MLCT absorption peaks is about $2.71 \mathrm{eV}$ $\left(\mathrm{S}_{0} \rightarrow \mathrm{S}_{n}, n=2\right.$ or 3$)$ with a weaker shoulder at $2.31 \mathrm{eV}$ $\left(S_{0} \rightarrow S_{1}\right) .{ }^{38}$ The excitation energy from $S_{0}$ to $S_{n}$ is relatively higher for BHandHLYP and M06-2X functionals, while the CAM-B3LYP functional seems to improve the prediction of the $S_{0} \rightarrow S_{n}$ excitation energy. The better performance of the CAM-B3LYP functional ${ }^{55}$ could be rationalized by its improvement on the charge transfer states $\left(\mathrm{S}_{1}, \mathrm{~S}_{2}\right.$, and $\left.\mathrm{S}_{3}\right)$ in the description of the $\left[\mathrm{Cu}(\mathrm{dmp})_{2}\right]^{+}$complex. However, a perfect agreement between theory and experiments should not be expected, since absorption spectra are measured in solvents. The difference between theoretical and experimental results is largely reduced, when our calculations took both the $\left[\mathrm{Cu}(\mathrm{dmp})_{2}\right]^{+}$cation and its counterpart anion $\left(\mathrm{PF}_{6}{ }^{-}\right)$ into account. After the inclusion of its counterpart anions (i.e. $\mathrm{PF}_{6}{ }^{-}$),

Table 1 The calculated and experimental excitation energies $(\mathrm{eV})$ of the $\left[\mathrm{Cu}(\mathrm{dmp})_{2}\right]^{+}$and $\left[\mathrm{Cu}(\mathrm{dmp})_{2}\right]\left(\mathrm{PF}_{6}\right)$ complex. The effect of the dichloromethane solution was taken into account with a single point calculation at the TDDFT/CAM-B3LYP level using the PCM model (in the bracket)

\begin{tabular}{|c|c|c|c|c|c|}
\hline \multirow[b]{2}{*}{ Species } & \multicolumn{3}{|l|}{$\underline{\left[\mathrm{Cu}(\mathrm{dmp})_{2}\right]^{+}}$} & \multicolumn{2}{|c|}{$\left[\mathrm{Cu}(\mathrm{dmp})_{2}\right]\left(\mathrm{PF}_{6}\right)$} \\
\hline & BHandHLYP & M06-2X & CAM-B3LYP & CAM-B3LYP & Exp. ${ }^{a}$ \\
\hline $\mathrm{S}_{1}$ & 3.11 & 3.03 & 2.62 & $2.43(2.47)$ & 2.31 \\
\hline $\mathrm{S}_{2}$ & 3.20 & 3.14 & 2.73 & $2.57(2.60)$ & 2.71 \\
\hline $\mathrm{S}_{3}$ & 3.42 & 3.39 & 2.94 & $2.96(2.98)$ & \\
\hline
\end{tabular}

${ }^{a}$ Values are taken from ref. 38 . 
the $S_{0} \rightarrow S_{1}$ excitation energy $(\sim 2.43 \mathrm{eV})$ was comparable to the experimental one $(\sim 2.31 \mathrm{eV})$. Note that the incorporation of the solvent effect (in dichloromethane) only shows minor contribution. This excitation energy dependence on the existence of the $\mathrm{PF}_{6}{ }^{-}$ anion may be partially caused by the structural distortion effects ( $\varphi=85.9^{\circ}$, in Fig. S3, ESI $\left.\dagger\right)$, which is consistent with X-ray crystallographic data $\left(\varphi=68^{\circ}-88^{\circ}\right)$ for the $\left[\mathrm{Cu}(\mathrm{dmp})_{2}\right]^{+}$complex with various counterpart anions.,23,61,62 The excitation energy would be lowered by $\sim 0.1 \mathrm{eV}$ along with the decreasing of the interligand dihedral angle (Fig. 3a). And the presence of the anion may also stabilize the MLCT excited state species and lower the excitation energies. Further transition density analysis of the $\left[\mathrm{Cu}(\mathrm{dmp})_{2}\right]\left(\mathrm{PF}_{6}{ }^{-}\right)$complex confirms that the low-lying excited states $\left(\mathrm{S}_{1}, \mathrm{~S}_{2}\right.$, and $\left.\mathrm{S}_{3}\right)$ are still typically MLCT states (Fig. S4, ESI $\dagger$ ). The anion effects show minor contribution to the shift of the absorption peak (Fig. S5, ESI $\dagger$ ). Although the existence of the anion has little effect on the position of the main absorption, the anion slightly changes the relative intensity of the shoulder compared to the absorption spectra of $\left[\mathrm{Cu}(\mathrm{dmp})_{2}\right]^{+}$. Based on a few experimental reports, ${ }^{23,24,63}$ the weak shoulder is attributed to the weak absorption of the first singlet MLCT transition for the geometries with a slightly flattened pseudotetrahedral structure. Overall, the result of the CAM-B3LYP functional is reasonable in our studies of the $\left[\mathrm{Cu}(\mathrm{dmp})_{2}\right]^{+}$complex.

The photoinduced structural flattening is an important feature of the $\mathrm{Cu}\left[(\mathrm{dmp})_{2}\right]^{+}$complex. Herein, we performed a
PES analysis along the interligand dihedral angle ( $\varphi$, see Fig. 2) for the low-lying singlet excited states. The geometries were relaxed on the ground state along this interligand dihedral angle. As shown in Fig. 3a, the topology of the PES for $S_{1}$ and $S_{2}$ states is relatively flat at or near tetrahedral geometry (FC region with $\varphi=90^{\circ}$ ). Furthermore, the excitation energy of the $\mathrm{S}_{1}$ state is lowered when the $\mathrm{Cu}\left[(\mathrm{dmp})_{2}\right]^{+}$complex distorts away from its tetrahedral geometry. In order to gain more insight into the geometric dependence of ${ }^{1}$ MLCT states, the transition density corresponding to the metal-to-ligand chargetransfer component is shown in Fig. $3 \mathrm{~b}$ as a function of the interligand dihedral angle. For the $S_{1}$ state, the charge transfer between the metal and ligands is only weakly dependent on the interligand angle. Meanwhile, the dependence of $\mathrm{S}_{2}$ and $\mathrm{S}_{3}$ states becomes more visible.

\section{Photoinduced excited state dynamics of the $\left[\mathrm{Cu}(\mathrm{dmp})_{2}\right]^{+}$ complex}

Here, we try to investigate the early-stage ultrafast dynamics on the coupled low-lying singlet surface, and its subsequent structural flattening on the $S_{1}$ state. The experimental works usually study the excited-state dynamics starting from the higher $S_{n}\left(S_{2}\right.$ or $\left.S_{3}\right)$ state. $^{31,38}$ Thus, we begin our ultrafast nonadiabatic dynamics simulations from the $\mathrm{S}_{n}$ state. Previous experimental studies proposed that, after $\left[\mathrm{Cu}(\mathrm{dmp})_{2}\right]^{+}$is excited into the $S_{n}$ state, the excited state decay process is composed of several processes with

(a)

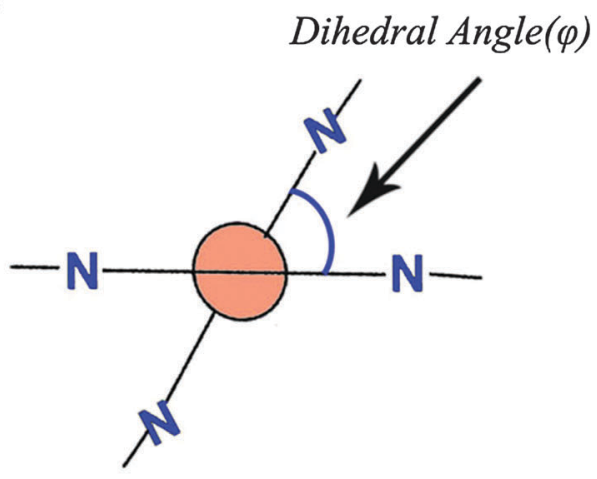

(b)

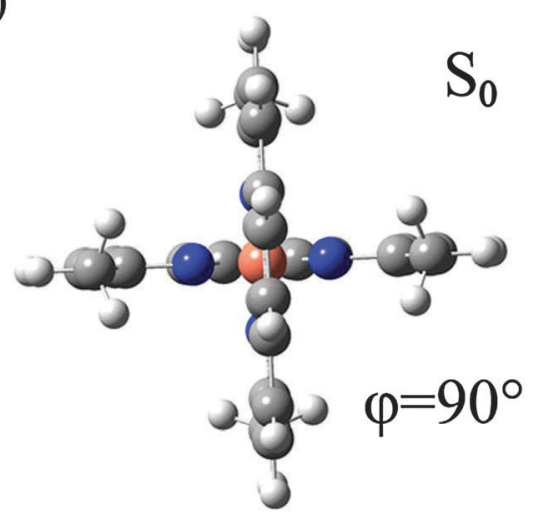

(c)

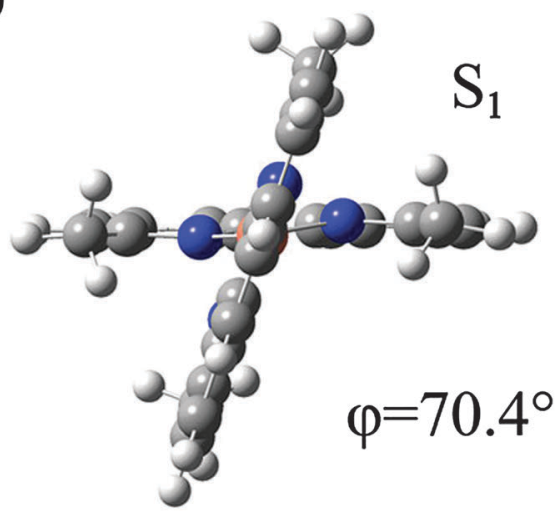

Fig. 2 (a) The definition of the interligand dihedral angle $(\varphi)$ between dmp ligands; and the optimized structures of the $\left[\mathrm{Cu}(\mathrm{dmp})_{2}\right]^{+} \mathrm{complex}$ at the CAM-B3LYP level for (b) the ground state $\left(S_{0}\right)$; (c) the low-lying $S_{1}$ excited state. 

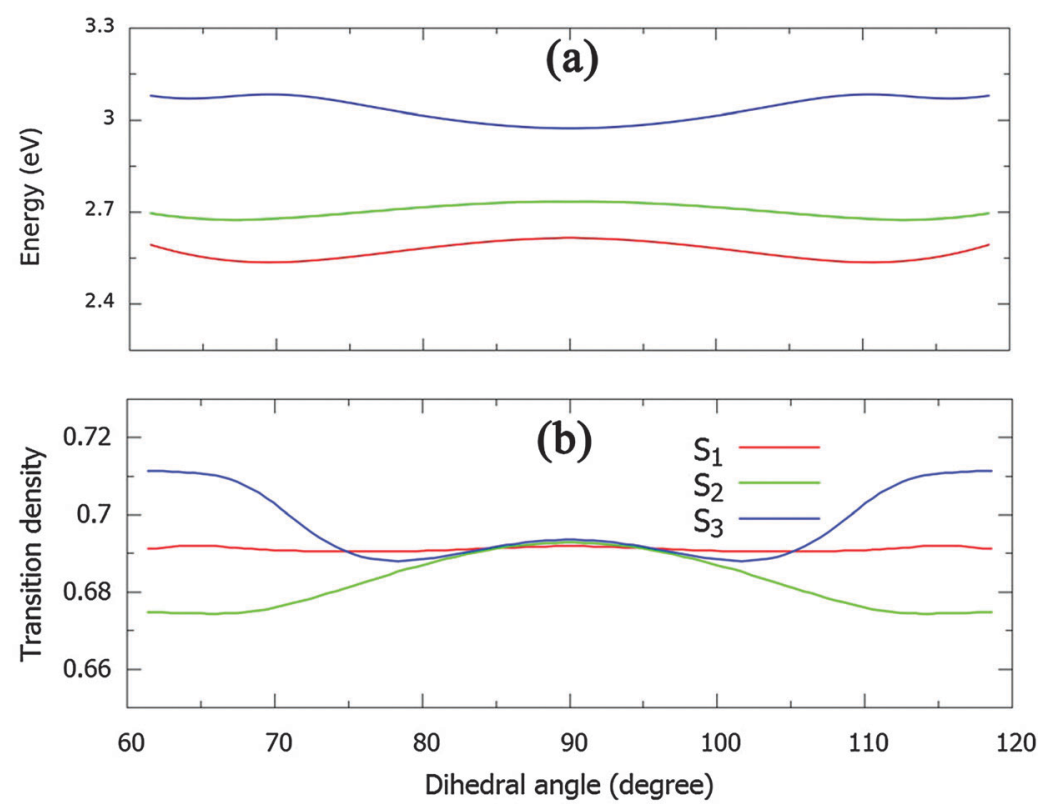

Fig. 3 (a) The potential energy curves of $S_{1}, S_{2}$, and $S_{3}$ states, as a function of interligand dihedral angle $(\varphi)$. (b) The transition density amplitude of the metal-to-ligand charge-transfer component for $S_{1}, S_{2}$, and $S_{3}$ states as a function of interligand dihedral angle $(\varphi)$, which can be used to measure the contribution of the charge-transfer component for each state.

distinguishable time scales, namely the ultrafast IC to the $\mathrm{S}_{1}$ state, the structural flattening distortion on the $S_{1}$ state, and the subsequent ISC process around $10-20 \mathrm{ps}^{20,29-31,35,38,64}$

\section{The initial ultrafast nonadiabatic dynamics}

Fig. 4a shows the average fraction of trajectories for each state, after excited into the $S_{2}$ state. For $\left[\mathrm{Cu}(\mathrm{dmp})_{2}\right]^{+}$, the initial quick drop of the $\mathrm{S}_{2}$ population is observed within first $\sim 30 \mathrm{fs}$. And then, the continuous decay of the $S_{2}$ state takes place from $20 \%$ to $5 \%$ along with fast oscillations. Later, the $\mathrm{S}_{2}$ population is kept below $10 \%$ beyond 100 fs. This ultrafast decay of the $\mathrm{S}_{2}$ state is relatively faster than the experimental data $(\tau \approx 47 \mathrm{fs}) .{ }^{31}$ This is expected, due to the ignoring of the hindrance effects of solvent molecules, the missing of the anion or the lacking of the possible contribution from the minor ISC channels.
The $S_{1}$ population increases to more than $90 \%$ beyond 100 fs. In Fig. $4 \mathrm{a}$, the $\mathrm{S}_{3}$ state shows a low probability in the initial stage of the trajectories, which can be rationalized by the PES profile of the $S_{3}$ state (Fig. 3a). At the FC geometry, the energy gap between $S_{2}$ and $S_{3}$ is smaller. In addition, it may also become closer during the trajectory propagation (Fig. S6, ESI $\dagger$ ). We also tried to examine the dependence of the excited-state decay on DFT functionals. Compared with CAM-B3LYP results, the M06-2X functional predicts the similar ultrafast decay behavior, although slightly slower decay of the $S_{2}$ state is observed.

Finally, the excited state dynamics from the $S_{3}$ state was also considered (Fig. $3 \mathrm{~b}$ ). The decay to the $\mathrm{S}_{1}$ state takes place with a time constant of about $50 \mathrm{fs}$, which is similar to the recent experimental assignment of the initial IC process to the $S_{1}$ state. ${ }^{31}$ Although the ground electronic state $\left(\mathrm{S}_{0}\right)$ was also included in the (a)

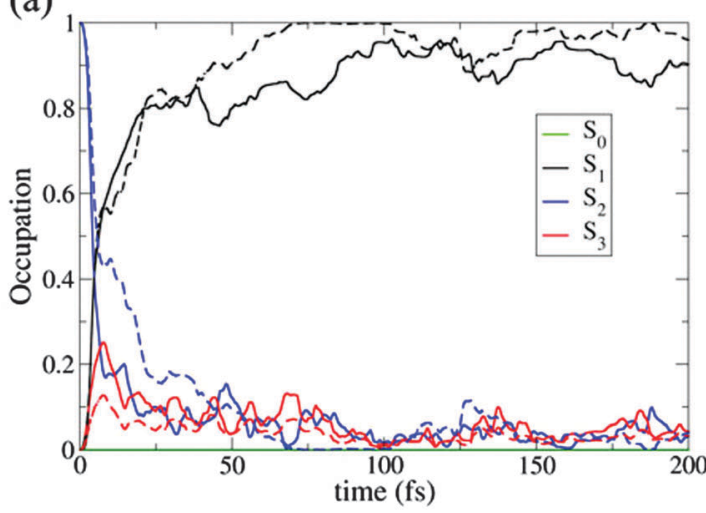

(b)

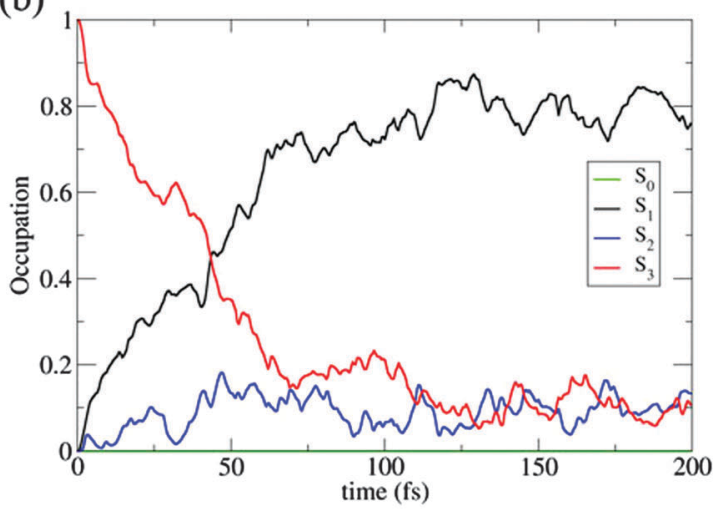

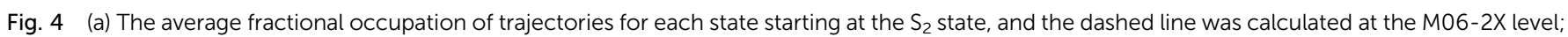
(b) the average fractional occupation of trajectories for each state starting at the $S_{3}$ state. 
current surface hopping dynamics, we do not see any trajectory jumping to $\mathrm{S}_{0}$ within the simulation time scale (Fig. S7 and S8, $\mathrm{ESI} \dagger$ ). Overall, no matter which state the trajectories start from, after the quick drop of fractional occupation of the initial state $\left(S_{n}\right)$, the system stays on the $S_{1}$ PES. Overall, the subsequent excited state dynamic behavior is quite similar. And thus we would perform further trajectory analysis based on the simulation (TDDFT/CAM-B3LYP level) starting from the $\mathrm{S}_{2}$ state in the following discussions.

$\mathrm{Next}$, the distribution of the $\mathrm{Cu}-\mathrm{N}$ distance and interligand dihedral angle $(\varphi)$ was analyzed during the $S_{n} \rightarrow S_{1}$ hopping events. Fig. 5a indicates that nearly perpendicular geometries are preferred at the avoided crossing points $\left(\mathrm{S}_{n} / \mathrm{S}_{1}\right)$; however, the slightly distorted geometries are also possible. Generally, the hopping geometries remain the same as the initial FC geometry at the $\mathrm{S}_{0}$ state. During the ultrafast IC dynamics from the $S_{n}$ to the $S_{1}$ state, a significant $\mathrm{Cu}-\mathrm{N}$ stretching motion was observed, which mainly splits into two branches (Fig. 5b). This can be rationalized by the following fact. When the system moves away from the FC geometry, the $S_{1}$ state displays the electronic character corresponding to the MLCT transition of a single electron from the copper ion (HOMO) to one of the dmp ligands (LUMO) (Fig. S1, ESI $\dagger$ ). This electrostatic interaction between the copper ion and ligands may induce a sudden force to drive the $\mathrm{Cu}-\mathrm{N}$ stretching motion. The asymmetrical electronic excitation should induce different force for the $\mathrm{Cu}-\mathrm{N}$ bonds on two ligands, resulting in the splitting feature shown in Fig. 5b. After this, the structural flattening distortion begins to occur on the $S_{1}$ state with longer time-scale dynamics.

\section{The $S_{1}$ state structural flattening dynamics}

In the following discussion, we focus on the structural flattening dynamics on the $S_{1}$ PES within one picosecond. Recent experimental studies reveal that the timescales of the successive structural change and the ISC process seem to be well-separated, occurring with time constants of $\sim 600-800$ fs and $\sim 10-20$ ps. $^{30,36}$ Based on these experimental observations, the ISCs into the triplet states should be rare within the sub-picosecond timescale. Instead, the ISC process may occur on the time scale of $\sim 10 \mathrm{ps}$, which is beyond our on-the-fly surface hopping dynamics simulations. Therefore, we pay our attention to the early-stage dynamics, especially, the unique structural flattening in the $S_{1}$ state for various $\mathrm{Cu}(\mathrm{I})$ complexes, which is supposed to be the major contribution $(\sim 70 \%)^{20}$ within the subpicosecond time scale.

The time evolution of the distribution of the interligand dihedral angle $(\varphi)$ was shown in Fig. 6a. We also provided time evolution of the interligand dihedral angle for several specific trajectories (Fig. S9, ESI $\dagger$ ). Initially, the structural flattening motion is minor within the first 200 fs. Then the structural flattening angle begins to appear, and becomes stable around 600-750 fs. If we take the middle value as the structural flattening time constant ( $\sim 675 \mathrm{fs})$, this agrees well with the experimental assignment of time constants of the structural flattening distortion within $1000 \mathrm{fs},{ }^{20,30,31,37-39}$ i.e. $660 \mathrm{fs}^{20}$ or $800 \mathrm{fs}^{30,39}$ Furthermore, the current calculations clearly show that the IC dynamics to the $S_{1}$ state $(<100 \mathrm{fs})$ and the beginning of structural flattening motion on the $S_{1}$ state $(\sim 200 \mathrm{fs})$ are indeed well-separated, as suggested by a series of recent experimental studies. ${ }^{30,31,36}$ Note that the interligand dihedral angle $(\varphi)$ becomes stable until about $70^{\circ}$ or $110^{\circ}$, which is very close to our optimized geometry of the $S_{1}$ state $\left(\varphi=70.4^{\circ}\right.$, Fig. 2$)$. Additionally, the trajectories mainly split into two branches in terms of the directional behavior during the structural flattening dynamics. The clockwise and anti-clockwise flattening motions are nearly identical, while different ratios for each branch may be expected if this symmetric character is destroyed, i.e. by the inclusion of its counterpart anion or asymmetric substitutes. We also tried to monitor the motion of each dmp ligand with respect to its initial frame (see ESI $\dagger$ ), as a function of time (Fig. 6b). For a specific trajectory, the rotation of one dmp ligand may range from less than $5^{\circ}$ to as large as $15^{\circ}$ (Fig. S9, ESI $\dagger$ ). On average, each dmp ligand rotates about $10^{\circ}$ to complete this structural flattening distortion.

Another interesting feature of the bis(diimine) $\mathrm{Cu}(\mathrm{I})$ complexes is their cooperatively steric hindrance influence of the substitute (a)

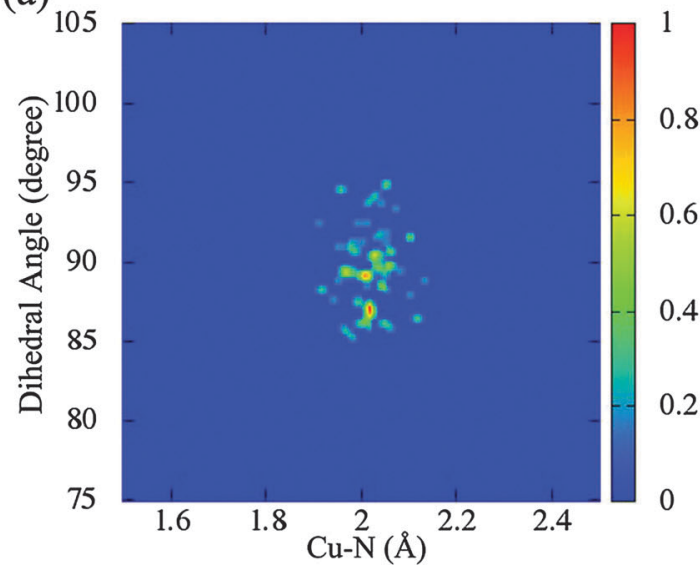

(b)

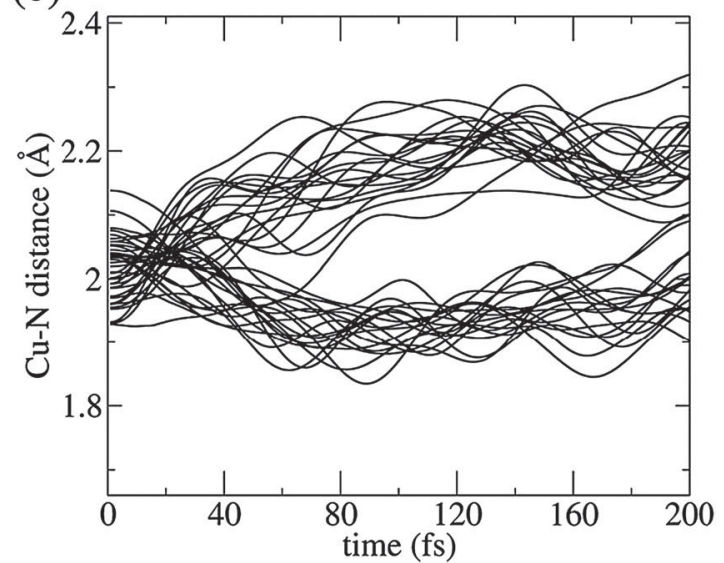

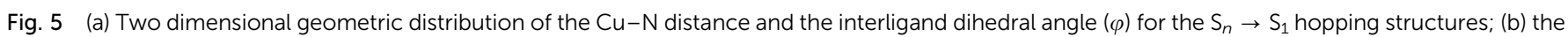
$\mathrm{Cu}-\mathrm{N}$ bond stretching of $\left[\mathrm{Cu}(\mathrm{dmp})_{2}\right]^{+}$as a function of time (fs). 
(a)

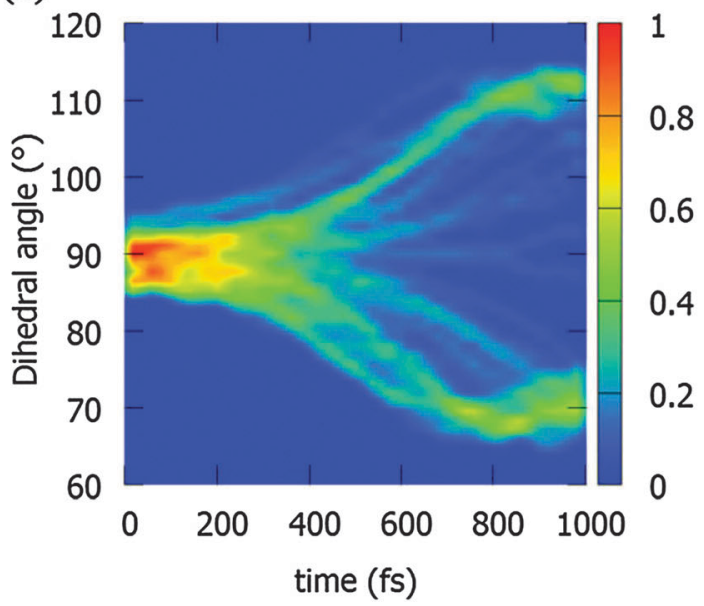

(b)

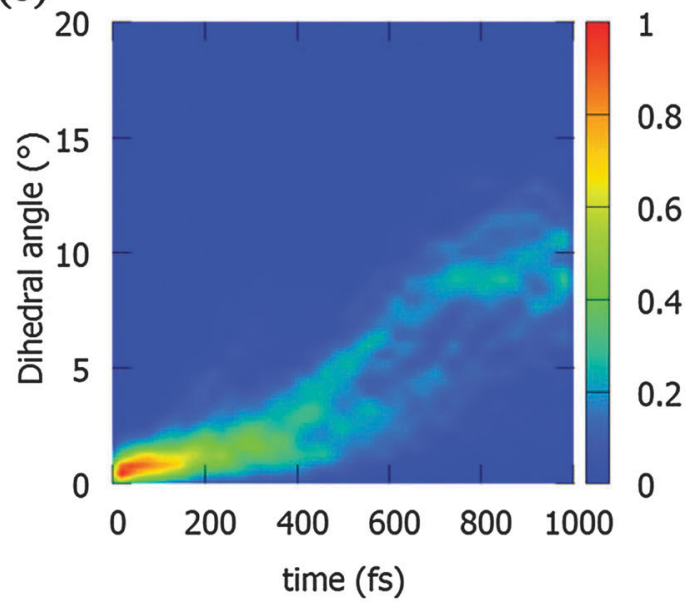

Fig. 6 (a) Time evolution of the interligand dihedral angle $(\varphi)$; (b) the dihedral angle of one dmp ligand with respect to its initial frame, as a function of time.

effects at the 2,9-positions of 1,10-phenanthroline, which can dramatically influence the excited state characteristics and dynamics. ${ }^{31,38,39,65,66}$ Here, the root-mean-square deviation (RMSD) is used to monitor the motion of the methyl group $\left(-\mathrm{CH}_{3}\right)$ with respect to its initial structure along the trajectories. We also analyzed the correlation between the relaxation of methyl group and the evolution of the interligand flattening angle $(\varphi)$. Our results indicate that the structural flattening process takes place in a stepwise manner (Fig. 7). Within the first $\sim 200 \mathrm{fs}$, the relaxation of four methyl groups starts prior to the structural flattening dynamics, which is obviously reflected by the increasing RMSD values, in contrast to the nearly constant interligand dihedral angle $(\varphi)$. Later, the dihedral angle $(\varphi)$ begins to increase along with the relaxation of methyl groups. After $\sim 700 \mathrm{fs}$, the dihedral angle remains stable $\left(\varphi \approx 70^{\circ}\right)$, while the methyl groups undergo further relaxation. Therefore, the active motion of the substituted groups should be considered to achieve the proper topographic description of the excited state PES. This feature also implies that the different substituted moieties attached in the ligand may have potential influences on the geometrical evolution dynamics for bis(diimine) $\mathrm{Cu}(\mathrm{I})$ complexes. A few recent experiments have been reported to utilize the substitute effects to improve the performance of copper(I)-based dye sensitized solar cells. ${ }^{17,18,35,38,64,66}$

Finally, we pay our attention to the time evolution of several critical geometric parameters. Significant fluctuations of the $\mathrm{Cu}-\mathrm{N}$ bond length and $\mathrm{N}-\mathrm{Cu}-\mathrm{N}$ bond angle were observed (Fig. 8), which implies the collective nuclear motion on the $\mathrm{S}_{1}$ state. ${ }^{31}$ Fig. 8 also shows the Fourier transformation of the oscillation of the $\mathrm{Cu}-\mathrm{N}$ bond length and the $\mathrm{N}-\mathrm{Cu}-\mathrm{N}$ bond angle. Due to the limited simulation timescale, the resolution of the Fourier transformation may not provide a very explicit assignment. However, we may provide a rough assignment of the several important frequency domains of vibrational motions on the basis of recent spectroscopic and theoretical studies. ${ }^{30,40}$ For instance, the vibration $\left(\sim 150 \mathrm{~cm}^{-1}\right)$ with the largest contribution (Fig. 8b) is very close to the largest

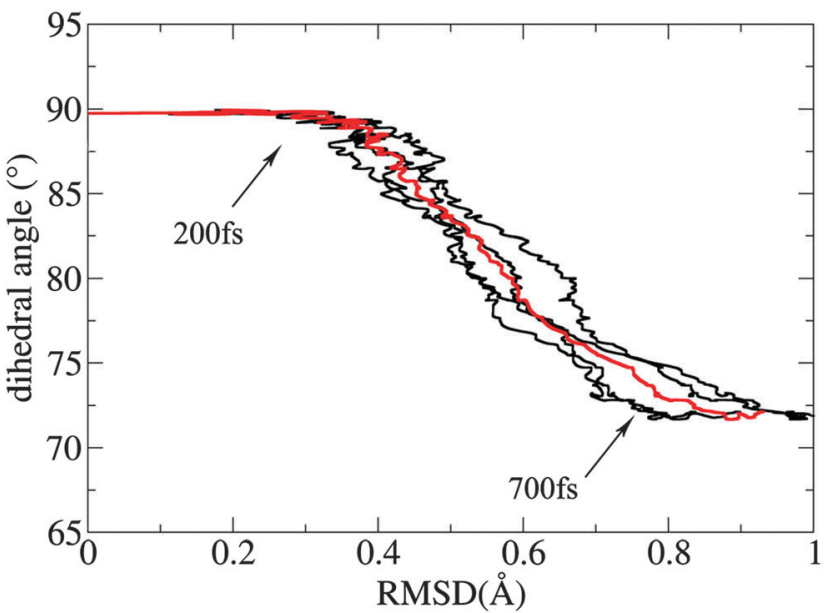

Fig. 7 The correlation between the motion of methyl groups $\left(-\mathrm{CH}_{3}\right)$ and the interligand dihedral angle $(\varphi)$, which is averaged over all trajectories. The black lines refer to four methyl groups, while the red line refers to their average values. Note that only the branch with a dihedral angle below $90^{\circ}$ was shown, due to its symmetric character.

contribution $\left(125 \mathrm{~cm}^{-1}\right)$ in the Fourier transformation of the oscillation in the transient absorption signal. ${ }^{30}$ Tahara and co-workers have assigned this vibration to the "breathing" motion of the complex, i.e. the collective oscillation of the $\mathrm{Cu}-\mathrm{N}$ bond. Note that this vibration is related to the oscillation with a period of $\sim 300 \mathrm{fs}$, which can be easily identified in Fig. $8 \mathrm{a}$ as well. The vibrations around $200-300 \mathrm{~cm}^{-1}$ could be assigned to the rocking motions. The smaller peak at around $430 \mathrm{~cm}^{-1}$ is related to the bending motion involving the $\mathrm{N}-\mathrm{Cu}-\mathrm{N}$ bond angle. The vibrations with higher frequency $\left(\sim 800 \mathrm{~cm}^{-1}\right)$ could be attributed to the vibrations containing $\mathrm{Cu}-\mathrm{N}$ stretching motion. All of these modes are also consistent with the important mode assignments of Capano et al. ${ }^{40}$

The geometrical flexibility of the dmp ligands was also investigated to rationalize the dynamical details in the structural flattening motion. The out-of-plane motion of a dmp ligand is 
(a)
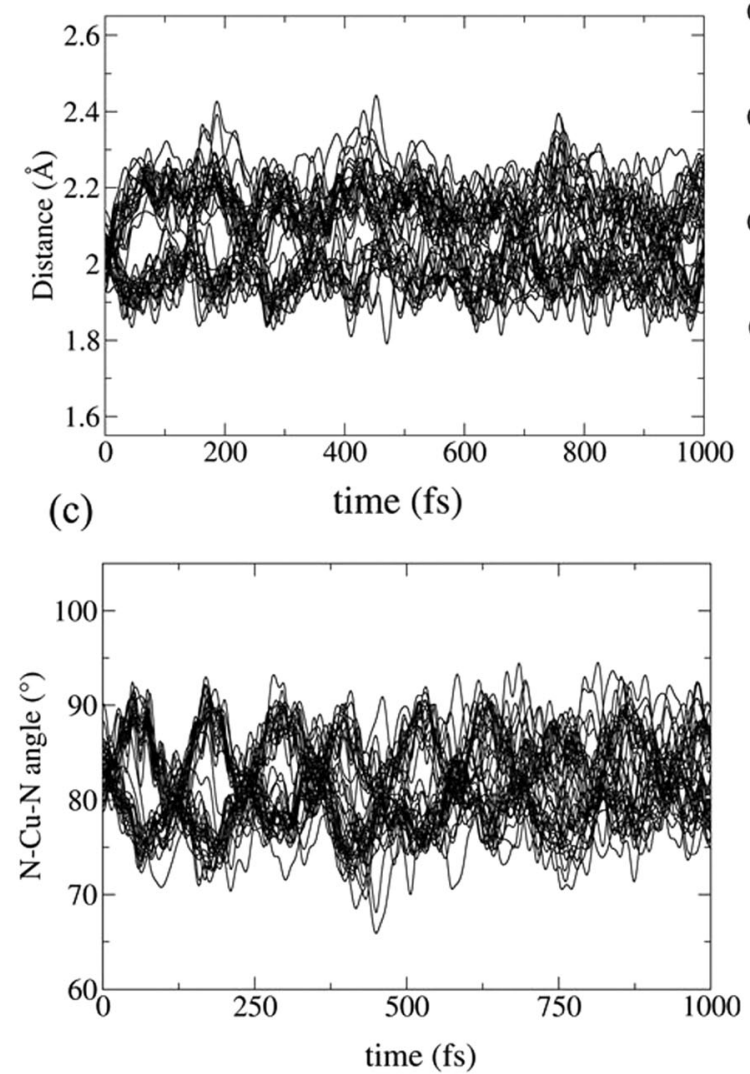

(b)
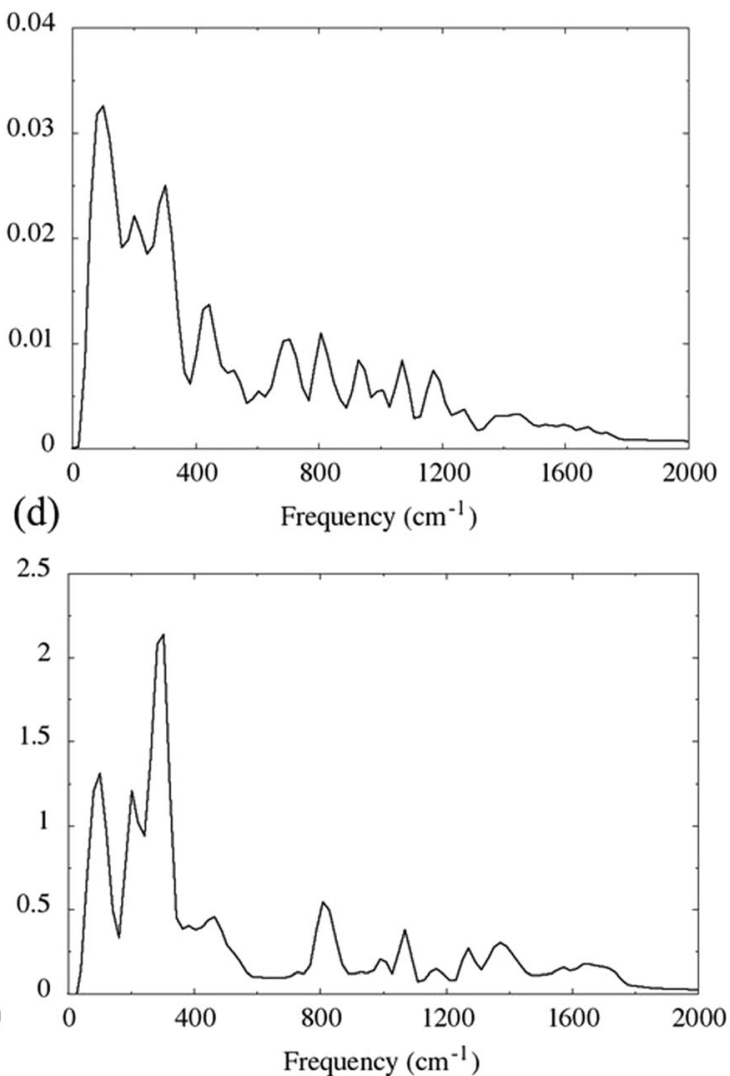

Fig. 8 Time evolution of the $\mathrm{Cu}-\mathrm{N}$ bond length (a) and the $\mathrm{N}-\mathrm{Cu}-\mathrm{N}$ bond angle (b); the Fourier transformation of the $\mathrm{Cu}-\mathrm{N}$ bond length (c) and the $\mathrm{N}-\mathrm{Cu}-\mathrm{N}$ bond angle (d). The zero component of the Fourier transform has been truncated for illustrative purposes.

Table 2 Time constants (ps) of several critical mechanistic processes obtained from excited state dynamics simulations, and recent experimental conclusions of the low-lying excited states of the $\left[\mathrm{Cu}(\mathrm{dmp})_{2}\right]^{+}$complex

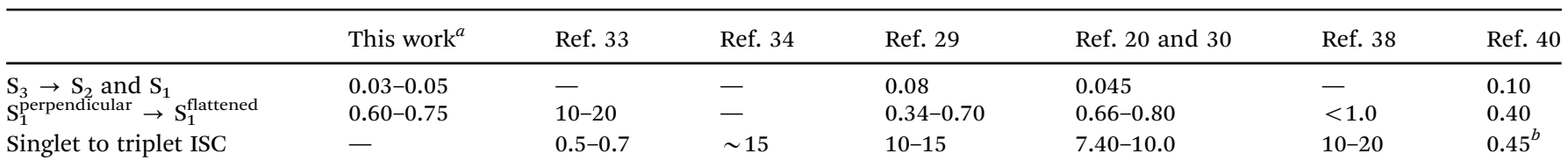

${ }^{a}$ The current work does not address the ISC process. ${ }^{b}$ The ISC channel near the FC geometry is reported from results of quantum dynamics with reduced Hamiltonian model.

described by the residue with respect to the planar equation (Fig. S10a in the ESI $\dagger$ ). During the trajectory propagation, the deviation from an ideal plane was less than $0.1 \AA$ per atom, which is less than $10 \%$ of a typical $\mathrm{C}-\mathrm{C}$ bond length. The wagging and rocking vibrations cause very small structural fluctuations $\sim 3^{\circ}$ (Fig. S10b, ESI $\dagger$ ), in contrast to $\sim 20^{\circ}$ for the structural flattening motion. Therefore, the structural flattening motion is dominant in the dynamics, although the other nuclear motion is also involved in realistic dynamic processes. In addition, significant periodic motions $(\sim 300 \mathrm{fs})$ were also observed in the wagging and rocking motions, which were assigned as the "breathing" motion. Thus, such collective oscillation of the $\mathrm{Cu}-\mathrm{N}$ bond should be a typical character in the structural flattening dynamics of the $\left[\mathrm{Cu}(\mathrm{dmp})_{2}\right]^{+}$complex (Table 2).

\section{Conclusions}

The bis(diimine) $\mathrm{Cu}(\mathrm{I})$ complexes, such as $\left[\mathrm{Cu}(\mathrm{dmp})_{2}\right]^{+}$, have received great research interest, because their photophysical characteristics are highly suitable for photosensitizers and photocatalysts. Here, we performed a detailed investigation of the initially photoinduced excited state dynamics of $\left[\mathrm{Cu}(\mathrm{dmp})_{2}\right]^{+}$ involving the ultrafast IC $\left(\mathrm{S}_{n} \rightarrow \mathrm{S}_{1}\right)$ and the structural flattening process occurring on the $S_{1}$ state, which is an intriguing feature of these $\mathrm{Cu}(\mathrm{I})$ complexes. The full dimensional excited-state dynamics of the transition metal complex are still challenging due to the large number of the degree of freedom. Thus, the on-the-fly nonadiabatic surface hopping dynamics was employed to study this electron-nuclei coupled relaxation dynamics at the sub-picosecond timescale, which provides us a direct view of the 
ultrafast photoinduced process of $\left[\mathrm{Cu}(\mathrm{dmp})_{2}\right]^{+}$, especially, the structural flattening mechanism on the $\mathrm{S}_{1}$ state.

Our excited state dynamic studies reveal that the photoinduced structural flattening process is composed of several events with distinguishable time scales (Table 2). At the early stage of the excited state dynamics of the $\left[\mathrm{Cu}(\mathrm{dmp})_{2}\right]^{+}$complex, the system undergoes an ultrafast internal conversion to the $\mathrm{S}_{1}$ state. On this very short timescale $(<200 \mathrm{fs})$, significant motions of the $\mathrm{Cu}-\mathrm{N}$ bond length and the $\mathrm{N}-\mathrm{Cu}-\mathrm{N}$ bond angle are also observed. Later, the structural flattening process on the $\mathrm{S}_{1}$ state begins to appear after $\sim 200-300 \mathrm{fs}$, along with the relaxation of methyl groups. Note that the cooperative relaxation of methyl groups starts prior to the structural flattening dynamics, which should be important to avoid the steric hindrance of the substitutes. The interligand flattening angle $(\varphi)$ becomes stable at around 600-750 fs, and we take the middle value as the structural flattening time constant ( $\sim 675 \mathrm{fs}$ ), which agrees well with a series of recent experimental values. ${ }^{20,29-31,36,38}$ Fourier transformations of the oscillation of the $\mathrm{Cu}-\mathrm{N}$ bond length and $\mathrm{N}-\mathrm{Cu}-\mathrm{N}$ bond angle also identify several most important vibrational frequency domains, which are consistent with the recent theoretical and experimental assignments. ${ }^{30,40}$ At the same time, the planarity of two dmp ligands basically remains during the whole flattening dynamics.

Overall, the static and dynamic excited state calculations provide an illustrative picture of the photoinduced structural change in the ${ }^{1}$ MLCT state. Since such a photoinduced structural change is an essential component in photophysics and photochemistry of the $\mathrm{Cu}(\mathrm{I})$ complexes, this detailed understanding of the ultrafast excitedstate process is indispensable to the future development of the $\mathrm{Cu}(\mathrm{I})$ based photovoltaic materials as alternatives to the ruthenium(II) complexes. Finally, the full dimensional excited-state dynamics simulation of a large transition metal complex is a challenging topic in theoretical aspects. Further research is also going on to consider a few important issues in the structural flattening dynamics, for example the anion/solvent effects, and the possible ISC contribution.

\section{Acknowledgements}

This work is supported by the CAS 100 Talent Project, and NSFC project (Grant No. 91233106, 21503249 and 21543008). This work was also supported by the Natural Science Foundation of Shandong Province for Distinguished Young Scholars (JQ201103). The authors thank the support by Natural Science Foundation of Shandong Province for Young Scientist (ZR2015BQ010). The authors also thank Supercomputing Centre, Computer Network Information Center, CAS and the Super Computational Centre of CAS-QIBEBT for providing computational resources.

\section{Notes and references}

1 J. A. Paulson, D. A. Krost, G. L. McPherson, R. D. Rogers and J. L. Atwood, Inorg. Chem., 1980, 19, 2519-2525.
2 C. T. Cunningham, J. J. Moore, K. L. H. Cunningham, P. E. Fanwick and D. R. McMillin, Inorg. Chem., 2000, 39, 3638-3644.

3 D. V. Scaltrito, D. W. Thompson, J. A. O'Callaghan and G. J. Meyer, Coord. Chem. Rev., 2000, 208, 243-266.

4 M. W. Mara, K. A. Fransted and L. X. Chen, Coord. Chem. Rev., 2015, 282-283, 2-18.

5 J. A. Simon, S. L. Curry, R. H. Schmehl, T. R. Schatz, P. Piotrowiak, X. Jin and R. P. Thummel, J. Am. Chem. Soc., 1997, 119, 11012-11022.

6 A. El-ghayoury, A. Harriman and R. Ziessel, Chem. Commun., 1999, 2027-2028.

7 A. Adronov and J. M. J. Frechet, Chem. Commun., 2000, 1701-1710.

8 D. S. Tyson, K. B. Henbest, J. Bialecki and F. N. Castellano, J. Phys. Chem. A, 2001, 105, 8154-8161.

9 J. K. McCusker, Acc. Chem. Res., 2003, 36, 876-887.

10 R. Passalacqua, F. Loiseau, S. Campagna, Y.-Q. Fang and G. S. Hanan, Angew. Chem., Int. Ed., 2003, 42, 1608-1611.

11 M. T. Miller, P. K. Gantzel and T. B. Karpishin, Angew. Chem., Int. Ed., 1998, 37, 1556-1558.

12 M. Ruthkosky, C. A. Kelly, F. N. Castellano and G. J. Meyer, Coord. Chem. Rev., 1998, 171, 309-322.

13 M. T. Miller, P. K. Gantzel and T. B. Karpishin, J. Am. Chem. Soc., 1999, 121, 4292-4293.

14 D. G. Cuttell, S.-M. Kuang, P. E. Fanwick, D. R. McMillin and R. A. Walton, J. Am. Chem. Soc., 2002, 124, 6-7.

15 B. Kumar, M. Llorente, J. Froehlich, T. Dang, A. Sathrum and C. P. Kubiak, Annu. Rev. Phys. Chem., 2012, 63, 541-569.

16 M. Grätzel, J. Photochem. Photobiol., C, 2003, 4, 145-153.

17 E. Holder, B. M. W. Langeveld and U. S. Schubert, Adv. Mater., 2005, 17, 1109-1121.

18 C. E. Housecroft and E. C. Constable, Chem. Soc. Rev., 2015, 44, 8386-8398.

19 M. W. Mara, D. N. Bowman, O. Buyukcakir, M. L. Shelby, K. Haldrup, J. Huang, M. R. Harpham, A. B. Stickrath, X. Zhang, J. F. Stoddart, A. Coskun, E. Jakubikova and L. X. Chen, J. Am. Chem. Soc., 2015, 137, 9670-9684.

20 M. Iwamura, S. Takeuchi and T. Tahara, J. Am. Chem. Soc., 2007, 129, 5248-5256.

21 C. E. McCusker and J. K. McCusker, Inorg. Chem., 2011, 50, 1656-1669.

22 A. M. Brown, C. E. McCusker and J. K. McCusker, Dalton Trans., 2014, 43, 17635-17646.

23 W. L. Parker and G. A. Crosby, J. Phys. Chem., 1989, 93, 5692-5696.

24 R. M. Everly and D. R. McMillin, J. Phys. Chem., 1991, 95, 9071-9075.

25 R. M. Everly, R. Ziessel, J. Suffert and D. R. McMillin, Inorg. Chem., 1991, 30, 559-561.

26 S. Sakaki, H. Mizutani and Y. Kase, Inorg. Chem., 1992, 31, 4575-4581.

27 B. J. Hathaway and D. E. Billing, Coord. Chem. Rev., 1970, 5, 143-207.

28 B. J. Hathaway, Coord. Chem. Rev., 1981, 35, 211-252.

29 G. B. Shaw, C. D. Grant, H. Shirota, E. W. Castner, G. J. Meyer and L. X. Chen, J. Am. Chem. Soc., 2007, 129, 2147-2160. 
30 M. Iwamura, H. Watanabe, K. Ishii, S. Takeuchi and T. Tahara, J. Am. Chem. Soc., 2011, 133, 7728-7736.

31 M. Iwamura, S. Takeuchi and T. Tahara, Acc. Chem. Res., 2015, 48, 782-791.

32 L. X. Chen, G. Jennings, T. Liu, D. J. Gosztola, J. P. Hessler, D. V. Scaltrito and G. J. Meyer, J. Am. Chem. Soc., 2002, 124, 10861-10867.

33 L. X. Chen, G. B. Shaw, I. Novozhilova, T. Liu, G. Jennings, K. Attenkofer, G. J. Meyer and P. Coppens, J. Am. Chem. Soc., 2003, 125, 7022-7034.

34 Z. A. Siddique, Y. Yamamoto, T. Ohno and K. Nozaki, Inorg. Chem., 2003, 42, 6366-6378.

35 C. E. McCusker and F. N. Castellano, Inorg. Chem., 2013, 52, 8114-8120.

36 M. Iwamura, S. Takeuchi and T. Tahara, Phys. Chem. Chem. Phys., 2014, 16, 4143-4154.

37 G. Capano, U. Rothlisberger, I. Tavernelli and T. J. Penfold, J. Phys. Chem. A, 2015, 119, 7026-7037.

38 S. Garakyaraghi, E. O. Danilov, C. E. McCusker and F. N. Castellano, J. Phys. Chem. A, 2015, 119, 3181-3193.

39 L. Hua, M. Iwamura, S. Takeuchi and T. Tahara, Phys. Chem. Chem. Phys., 2015, 17, 2067-2077.

40 G. Capano, M. Chergui, U. Rothlisberger, I. Tavernelli and T. J. Penfold, J. Phys. Chem. A, 2014, 118, 9861-9869.

41 A. Hoffmann, M. Rohrmüller, A. Jesser, I. dos Santos Vieira, W. G. Schmidt and S. Herres-Pawlis, J. Comput. Chem., 2014, 35, 2146-2161.

42 A. Jesser, M. Rohrmüller, W. G. Schmidt and S. Herres-Pawlis, J. Comput. Chem., 2014, 35, 1-17.

43 M. J. Frisch, G. W. Trucks, H. B. Schlegel, G. E. Scuseria, M. A. Robb, J. R. Cheeseman, G. Scalmani, V. Barone, B. Mennucci, G. A. Petersson, H. Nakatsuji, M. Caricato, X. Li, H. P. Hratchian, A. F. Izmaylov, J. Bloino, G. Zheng, J. L. Sonnenberg, M. Hada, M. Ehara, K. Toyota, R. Fukuda, J. Hasegawa, M. Ishida, T. Nakajima, Y. Honda, O. Kitao, H. Nakai, T. Vreven, J. A. Montgomery Jr., J. E. Peralta, F. Ogliaro, M. J. Bearpark, J. Heyd, E. N. Brothers, K. N. Kudin, V. N. Staroverov, R. Kobayashi, J. Normand, K. Raghavachari, A. P. Rendell, J. C. Burant, S. S. Iyengar, J. Tomasi, M. Cossi, N. Rega, N. J. Millam, M. Klene, J. E. Knox, J. B. Cross, V. Bakken, C. Adamo, J. Jaramillo, R. Gomperts, R. E. Stratmann, O. Yazyev, A. J. Austin, R. Cammi, C. Pomelli, J. W. Ochterski, R. L. Martin, K. Morokuma, V. G. Zakrzewski, G. A. Voth, P. Salvador, J. J. Dannenberg, S. Dapprich, A. D. Daniels, Ö. Farkas,
J. B. Foresman, J. V. Ortiz, J. Cioslowski and D. J. Fox, Gaussian 09, Gaussian, Inc., Wallingford, CT, USA, 2009.

44 M. Barbatti, G. Granucci, M. Persico, M. Ruckenbauer, M. Vazdar, M. Eckert-Maksić and H. Lischka, J. Photochem. Photobiol., A, 2007, 190, 228-240.

45 E. Tapavicza, I. Tavernelli and U. Rothlisberger, Phys. Rev. Lett., 2007, 98, 023001.

46 L. Du and Z. Lan, J. Chem. Theory Comput., 2015, 11, 1360-1374. 47 L. Du and Z. Lan, J. Chem. Theory Comput., 2015, 11, 4522-4523. 48 J. C. Tully, J. Chem. Phys., 1990, 93, 1061-1071.

49 H. Lischka, M. Dallos and R. Shepard, Mol. Phys., 2002, 100, 1647-1658.

50 U. Werner, R. Mitrić, T. Suzuki and V. Bonačić-Koutecký, Chem. Phys., 2008, 349, 319-324.

51 I. Tavernelli, E. Tapavicza and U. Rothlisberger, THEOCHEM, 2009, 914, 22-29.

52 G. Granucci, M. Persico and A. Zoccante, J. Chem. Phys., 2010, 133, 134111.

53 E. Wigner, Phys. Rev., 1932, 40, 749-759.

54 D. Sels and F. Brosens, Phys. Rev. E: Stat., Nonlinear, Soft Matter Phys., 2013, 88, 042101.

55 T. Yanai, D. P. Tew and N. C. Handy, Chem. Phys. Lett., 2004, 393, 51-57.

56 Y. Zhao and D. Truhlar, Theor. Chem. Acc., 2008, 120, 215-241.

57 F. Plasser and H. Lischka, J. Chem. Theory Comput., 2012, 8, 2777-2789.

58 F. Plasser, S. A. Bäppler, M. Wormit and A. Dreuw, J. Chem. Phys., 2014, 141, 024107.

59 F. Plasser, M. Wormit and A. Dreuw, J. Chem. Phys., 2014, 141, 024106.

60 J. Huang, L. Du, D. Hu and Z. Lan, J. Comput. Chem., 2015, 36, 1858.

61 A. J. Blake, S. J. Hill, P. Hubberstey and W.-S. Li, J. Chem. Soc., Dalton Trans., 1998, 909-916.

62 W. T. Eckenhoff and T. Pintauer, Acta Crystallogr., Sect. E: Struct. Rep. Online, 2007, 63, m800-m802.

63 K. A. Fransted, N. E. Jackson, R. Zong, M. W. Mara, J. Huang, M. R. Harpham, M. L. Shelby, R. P. Thummel and L. X. Chen, J. Phys. Chem. A, 2014, 118, 10497-10506. 64 M. Chergui, Acc. Chem. Res., 2015, 48, 801-808.

65 M. K. Eggleston, D. R. McMillin, K. S. Koenig and A. J. Pallenberg, Inorg. Chem., 1997, 36, 172-176.

66 C. E. McCusker and F. N. Castellano, Inorg. Chem., 2015, 54, 6035-6042. 